\title{
Anticholinergic brain stimulation and thirst induced by 23 hour water deprivation'
}

\author{
ROBERT A. LEVITT, DEPARTMENT OF PSYCHOLOGY, \\ SOUTHERN ILLINOIS UNIVERSITY, Carbondale, Illinois
}

Thirst was induced by $23 h$ water deprivation. Bilateral anticholinergic brain stimulation with atropine or scopolamine placed in the lateral septal nucleus or anterior thalamic nucleus had a small (9\%) but significant blocking effect on water intake if both food and water were available in the test cage. This effect was not present if only water was available.

In the rat, drinking can be induced by cholinergic stimulation of a number of limbic system loci (Fisher \& Coury, 1964). Levitt \& Fisher (1966) reported that brain stimulation with an anticholinergic drug applied to the "cholinergic drinking circuit" inhibited the drinking induced by cholinergic stimulation of any other structure in this circuit. More recently, these authors (Levitt \& Fisher, 1967) found that similar anticholinergic stimulation did not inhibit thirst induced by $23-\mathrm{h}$ of water deprivation. These results bring to question the relationship between the cholinergic thirst phenomenon and natural thirst.

The anticholinergic drug employed in these studies was atropine. There is evidence that scopolamine is as much as $\mathbf{2 0}$ times as potent as atropine in blocking cholinergic activity in several other systems (Cullumbine, 1967). There is also evidence that scopolamine is more potent than atropine in the blocking of cholinergic thirst (Levitt \& Fisher, in preparation). In the present study, both chemicals were employed.

Additionally, in the earlier 23-h water deprivation study, food was available in the home cage for $23 \mathrm{~h}$ and water (but not food) was present during the 1 -h test period. Animals on water deprivation reduce their intake of food and are thus also partially food deprived. Since only water was available in the test cage, it may be that the Ss were drinking a relatively small quantity, due to being partially food deprived. Therefore, the addition of food to the test cage may increase the quantity of water drunk and, as a result, the likelihood of anticholinergic stimulation having a depressant effect.

The present experiment varied two factors: (a) the anticholinergic drug employed (atropine or scopolamine) and (b) the appetitive stimuli present in the test cage (food and water or only water).

\section{Method}

Two hollow guide shafts aimed at the same structure on contralateral sides of the brain were surgically implanted in each adult male Long-Evans rat. The data reported are from $16 \mathrm{Ss}$ implanted bilaterally in the lateral septal nuclei (LSN) and 13 implanted bilaterally in the anterior thalamic nuclei (ATN).

The chemical to be used on a particular trial (carbachol, a cholinergic stimulant; atropine sulfate or scopolamine hydrobromide, cholinergic antagonists) was tamped into the tip of a 30 gg. cannula (5 tamps; about 1-3 $\mu \mathrm{g}$ ) and then inserted into the brain through the implanted guide shaft. The $30 \mathrm{gg}$. cannula was held to an assembly by a set screw and the assembly attached to the head of the implanted guide shaft. The cannula could be set to end at any length desired. Characteristically, the cannula was set to end even with the bottom of the guide shaft on the first trial. If an adequate drinking response was not obtained, the cannula was lowered through $2.0-3.0 \mathrm{~mm}$ of tissue in $0.5 \mathrm{~mm}$ steps. These techniques have been described previously (Fisher \& Coury, 1964; Levitt \& Fisher, 1966, 1967).

The Ss were housed individually in a "home cage" with powdered food and water available except during the deprivation phase of the study, when only food was in the home cage. The Ss were tested for drinking in a "test cage" of the same dimensions as the home cage. The test cage contained a calibrated drinking tube when the Ss were being tested for the elicitation of thirst by carbachol (while sated). During deprivation testing (anticholinergic blockade), either both powdered food and water or only water was in the test cage.
After recovering from surgery, the Ss were tested for drinking to carbachol at the two different loci (at least $6 \mathrm{ml}$ at each site). If two cholinergic drinking sites were located, the $S$ was put on 23-h water deprivation for seven days. The first six days were used to collect control data. The first two days' data were discarded and the next four days used to compute control intake ("None" column in Table 1). On Day 7 one of the anticholinergic drugs was injected either bilaterally or unilaterally, or empty cannuli were inserted bilaterally. The $S s$ were then given ad lib access to water and retested for drinking to carbachol. Data are reported only for Ss who drank $6 \mathrm{ml}$ or more to carbachol stimulation of a given site both before and following the deprivation trials.

Histological verification of the intended placements in LSN or ATN is available for most Ss.

Results

Control daily intake $(1 \mathrm{~h}$ access to food and water or only water following 23-h water deprivation) was $7.5 \mathrm{~g}$ and $19.2 \mathrm{ml}$ with food and water available in the test cage. Control daily intake was 18.4 $\mathrm{ml}$ with only water in the test cage. The water intake during trials on which food was also available was not significantly different from those trials on which only water was available.

Animals were tested for drinking to carbachol both before and following the deprivation series. Deprivation blockade data are included only for cases in which cholinergic drinking was elicited on both occasions from the site or sites which received anticholinergic stimulation. Mean intake to carbachol in the LSN was $14 \mathrm{ml}$ before and $13 \mathrm{ml}$ following deprivation. In the ATN it was $13 \mathrm{ml}$ before and $12 \mathrm{ml}$ following deprivation.

Empty cannuli were inserted bilaterally into positive sites on 14 trials with both food and water available and did not depress either the food or water intake of water deprived $S s$.

The difference between the effect of atropine and scopolamine in the depression of water intake was not statistically significant (Table 1). There was also no significant difference in the effect of stimulation of the two anatomical loci utilized (LSN and ATN).

With only water available, the anticholinergics when applied either unilaterally or bilaterally failed to significantly effect water intake.

With both food and water available, the anticholinergics failed to affect intake when applied unilaterally. However, bilateral application had a small but significant inhibitory effect on both water $(p<.001)$ and food $(p<.01)$ intake (Table 1$)$.

\section{Discussion}

Under the present conditions the availability of food did not increase drinking induced by water deprivation above the level found if only water was available.

Neither atropine, nor scopolamine significantly reduced deprivation-induced thirst if only water was available. If food was also in

Table 1

Effect of Cholinergic Blocking Agents on Thirst Induced by 23-h of Water Deprivation*

\begin{tabular}{|c|c|c|c|}
\hline \multirow{2}{*}{ Food and Water } & \multicolumn{3}{|c|}{ Blocking Agent } \\
\hline & None & Atropine & Scopolamine \\
\hline Bilateral & $\begin{array}{r}8 \mathrm{gm} \\
19 \mathrm{ml}\end{array}$ & $\begin{array}{r}7 \mathrm{gm} \\
17 \mathrm{ml}\end{array}$ & $\begin{array}{r}6 \mathrm{gm} \\
16 \mathrm{ml}\end{array}$ \\
\hline Unilateral & $\begin{array}{r}7 \mathrm{gm} \\
19 \mathrm{ml}\end{array}$ & $\begin{array}{r}7 \mathrm{gm} \\
20 \mathrm{ml}\end{array}$ & $\begin{array}{c}6 \mathrm{gm} \\
18 \mathrm{ml}\end{array}$ \\
\hline Water & & & \\
\hline Bilateral & $18 \mathrm{ml}$ & $18 \mathrm{ml}$ & $18 \mathrm{ml}$ \\
\hline Unilateral & $18 \mathrm{ml}$ & $18 \mathrm{ml}$ & $17 \mathrm{ml}$ \\
\hline
\end{tabular}

*Each intake level in the Atropine and Scopolamine columns is the mean of between 10 and 20 trials. The data in the None column are the control intake means for the same trials from which the data in the last two columns are derived. 
the test cage, the anticholinergics produced small but significant reductions in food and water intake when applied bilaterally. The cause of these effects remains unclear.

It is rather interesting that scopolamine was no more effective than atropine in the blockade of thirst induced by water deprivation. Scopolamine has been shown to be considerably more potent than atropine in blocking several other cholinergic systems and is also more potent in the inhibition of cholinergically-induced thirst. These data further emphasize the resistance of thirst induced by $23 \mathrm{~h}$ of water deprivation to anticholinergic blockade.

The results reported here are in agreement with earlier reports that anticholinergic brain stimulation severely depresses cholinergically induced thirst but has little or no effect on thirst induced by water deprivation. Levitt \& Fisher $(1966,1967)$ have reported anticholinergic brain stimulation to depress cholinergically induced drinking by about $90 \%$, while it had no significant depressant effect on thirst induced by $23 \mathrm{~h}$ of water deprivation (only water present in the test cage).

In the present study anticholinergic stimulation had no effect on deprivation-induced thirst with water in the test cage, but a slight depressant effect (about 10\%) if both food and water were in the test cage.
There would seem to be two likely explanations for this difference in the effect of anticholinergic brain stimulation on cholinergic and "natural" thirst. Either these two "types of thirst" are not identical in their neurobiochemical substrates or the substrate for both thirsts is the same but in a sufficiently different state in the water sated and deprived animal to result in the behavioral differences reported here.

\section{REFERENCES}

COLLUMBINE, H. Muscarinic blocking drugs. In W. S. Root and F. G. Hofmann (Eds.), Physiological pharmacology, Vol. III. New York: Academic Press, 1967. Pp. 323-362.

FISHER, A. E., \& COURY, J. N. Chemical tracing of neural pathways mediating the thirst drive. In M. J. Wayner (Ed.), Thirst. New York: Pergamon Press, 1964. Pp. 515-529.

LEVITT, R. A., \& FISHER, A. E. Anticholinergic blockade of centrally induced thirst. Science, 1966, 154, 520-522.

LEVITT, R. A., \& FISHER, A. E. Failure of central anticholinergic brain stimulation to block natural thirst. Physiol. Behav., 1967, 2, 425-428.

LEVITT, R. A., \& FISHER, A. E. Biochemical blockade of cholinergic thirst (in preparation).

NOTE

1. This investigation was supported by NIMH Grant MH-14381-01. 